\title{
UMA EXPERIÊNCIA COM UM ESQUEMA COLABORATIVO NO ENSINO DE FUNÇÕ̃ES NO PEJA
}

\section{AN EXPERIMENT WITH A COLLABORATIVE SCHEME IN TEACHING OF FUNCTIONS IN THE YOUTH AND ADULT EDUCATIONAL PROGRAM (PEJA)}

\author{
COSTA, Marcus Vinícius Tovar ${ }^{1}$ \\ BARBOSA, Agusto Cesar de Castro ${ }^{2}$ \\ CASTRO DEL RIO, Victor Luiz $^{3}$
}

\section{RESUMO}

Esse trabalho apresenta uma experiência realizada no Programa de Educação de Jovens e Adultos com uma abordagem colaborativa, tendo como público alvo alunos de uma escola da rede municipal de ensino do Rio de Janeiro. Seu objetivo é fornecer ferramentas que possibilitem o uso do Ensino Colaborativo no ensino de Matemática. O trabalho mostra um estudo comparativo entre turmas do Ensino de Jovens e Adultos, na qual o Ensino Colaborativo foi utilizado em apenas uma delas. As atividades propostas visaram criar um ambiente adequado para que as interações entre os alunos e entre professor e alunos ocorressem de forma efetiva. A criação desse ambiente possibilitou que cada estudante fosse capaz de confrontar ideias, dividir conhecimentos e desenvolver ou adquirir habilidades. A utilização da prática colaborativa facilitou a introdução do conceito de função e mostrou aos discentes as diferentes formas de representá-la.

PALAVRAS-CHAVE: Ensino colaborativo; Função; Educação de Jovens e Adultos.

\footnotetext{
${ }^{1}$ Professor Associado do Instituto de Matemática e Estatística da Universidade do Estado do Rio de Janeiro. Tem experiência na área de Física, com ênfase em Materiais Magnéticos, atuando principalmente nos seguintes temas: magnetismo itinerante, campos hiperfinos, impurezas e física de superfícies. Tem atuado também na área de Ensino de Física e Matemática Aplicada. e-mail: mvtcosta@gmail.com

${ }^{2}$ Possui doutorado em Física pela Universidade Federal Fluminense (1997), mestrado em Física (UFF 1992), graduação em Física (UFF - 1988) e graduação em Matemática pelo Centro Universitário Celso Lisboa (1981). e-mail: accb@ime.uerj.br

${ }^{3}$ Possui mestrado Matematica (profmat) pela Universidade do Estado do Rio de Janeiro (UERJ- 2014). Atualmente é professor da Escola Municipal Orsina da Fonseca - Ensino Fundamental e Escola Municipal Alencastro Guimarães - Educação de Jovens e Adultos. e-mail: victordelrio602@gmail.com
}

\section{ABSTRACT}




\section{ABSTRACT}

This paper presents an experiment with a collaborative approach in the Youth and Adult Educational Program, having as target audience students from a school in Rio de Janeiro's municipal educational system. Its objective is to develop tools that allow the use of collaborative teaching in Mathematics teaching. The study shows a comparative analysis of Youth and Adult Education classes where collaborative teaching was used in only one of them. The proposed activities aimed to create an adequate environment so that interactions between students and between teacher and students could occur effectively. This environment allowed each student to be able to confront ideas, share knowledge and develop or acquire skills. The use of collaborative practices facilitated the introduction of the mathematical concept of function and showed the students different ways of representing it.

KeYwORDS: Collaborative teaching; Mathematics; Function; Youth and Adult Education.

\section{INTRODUÇÃO}

É notória a necessidade de novas abordagens dos conteúdos no ensino de Matemática tendo em vista, principalmente, o panorama do ensino básico brasileiro, em particular, a Educação de Jovens e Adultos, em que os alunos são reflexos de sua difícil realidade social. Dessa forma, deve-se buscar uma prática pedagógica que torne a sala de aula um espaço democrático e colaborativo, de maneira que todos os sujeitos envolvidos no processo de ensino-aprendizagem sejam capazes de se tornar protagonistas no processo de desenvolvimento de sua própria formação.

Nesse trabalho, chamamos de Ensino Colaborativo (EC) as práticas que têm como objetivo proporcionar o intercâmbio de saberes entre membros de um mesmo grupo e a maior participação deles no processo de aprendizagem, de maneira que o conhecimento possa ser construído de forma coletiva.

Os Parâmetros Curriculares Nacionais (PCN) indicam como um dos objetivos do ensino fundamental que os alunos sejam capazes de "posicionar-se de maneira crítica, responsável e construtiva nas diferentes situações sociais, utilizando o diálogo como forma de mediar conflitos e de tomar decisões coletivas" (PCN, 1998, p.7).

Sendo assim, nesse trabalho, veremos sugestões de estruturação de aulas usando o EC.Mostramos a estrutura curricular e o funcionamento do Programa de Educação de Jovens e Adultos (PEJA) do Município do Rio de Janeiro e como o EC pode ser útil nesse segmento. Além disso, procurou-se unir o estudo de funções à prática do estudo coletivo no Ensino de Jovens e Adultos.

O principal objetivo desse trabalho é mostrar ao docente a possibilidade de inserir em sala de aula uma proposta pedagógica alicerçada na teoria construtivista, que possa possibilitar o aluno desenvolver-se tanto na Matemática, 
quanto em sua cidadania. Neste tipo de processo, os alunos são estimulados a se posicionar frente a diferentes opiniões e entendimentos diferentes dos seus, o que pode levar a um aumento da sua capacidade de socialização.

\section{O ENSINO COLABORATIVO}

Podemos entender o EC como um conjunto de atividades construtivistas que tem por objetivo proporcionar o desenvolvimento cognitivo por meio do intercâmbio de experiências entre os indivíduos envolvidos em um dado processo. Essa abordagem envolve a construção coletiva de um determinado conhecimento, onde a heterogeneidade nos grupos desempenha um papel fundamental na instigação de discussões.

O cerne do EC é possibilitar o desenvolvimento nos indivíduos que participam desse processo a capacidade de aprender trabalhando em grupo, sem, no entanto, colocar de lado o caráter adjutor oriundo da interação e da convivência entre os indivíduos.

Geralmente, ao longo da prática colaborativa, surgem metodologias específicas de ensino que possibilitam a vários alunos, com diferentes níveis de aprendizado, se relacionarem torno de um mesmo objetivo educacional, que pode ser o entendimento de um assunto específico ou a resolução de exercícios propostos. Com essa possibilidade de interação o aluno pode ser capaz de confrontar ideias, partilhar conhecimento, adquirir novas habilidades e/ou aperfeiçoá-las.

Desde o século XVIII, práticas colaborativas vêm sendo utilizadas por professores e pesquisadores. Metodologias colaborativas também têm sido bastante valorizadas no mundo corporativo, onde a prática do trabalho em equipe tem sido encarada como um forte mecanismo na busca da qualidade e eficiência do resultado desejado(TORRES, ALCANTARA,IRALA, 2004).

Os primeiros relatos da utilização de técnicas de aprendizagem colaborativa datam de 1774, quando o professor de lógica e filosofia da Universidade de Glasgow George Jardine trabalhou com seus alunos a elaboração de textos coletivos. Jardine avaliava seus alunos em pares e adaptava, quando necessário, sua metodologia às necessidades dos alunos durante o processo de aprendizagem (GAILLET, 1994; TORRES, ALCANTARA, IRALA, 2004).

Pesquisas realizadas em 1994 pelos irmãos Roger Johnson e David Johnson (GALVÃO, 2012) apontam que no inicio do século XIX surgiram as primeiras experiências em escolas tradicionais, como Lancaster School e Common School Movement, da aplicação dos esquemas colaborativos em salas de aula. Nos Estados Unidos, no final do século XIX, as práticas colaborativas vieram através de uma política pública em que se promovia nas escolas a aprendizagem em grupo 
(JOHNSON; JOHNSON 1992, 1998, apud GILLIAM, 2002; TORRES, ALCANTARA, IRALA, 2004).

No final do século XIX, surgiu na Europa o movimento conhecido como Escola Nova, que trouxe à tona a discussão sobre a importância do papel do aluno no processo de ensino-aprendizagem. Os entusiastas desse movimento tinham como princípio uma educação democrática que observava as diferenças individuais, o que implicava que os conteúdos não poderiam ser simplesmente apresentados a uma classe, uma vez que cada aluno tem seu próprio tempo de aprendizagem (SANTOS, 2006). O professor nessa abordagem incorporava 0 papel de facilitador do processo de ensino-aprendizagem, cabendo a ele se manter sempre atento e focado no aluno para despertar seus conhecimentos e interesses.

John Dewey, um dos educadores cuja teoria embasou o movimento da Escola Nova, utilizava grupos colaborativos como parte de seu método de ensino, pois acreditavaque a construção da educação se dava pela constante reflexão e reorganização das experiências vividas (DEWEY, apud TEIXEIRA, 1978).

Nos anos de 1960, na Inglaterra, diversas iniciativas contribuíram para o desenvolvimento de práticas colaborativas, como, por exemplo, em 1964, quando a zoologista Minnie Louie Johnson Abercrombie aplicou na área médica os conceitos colaborativos que Edwin Mason, Charity James e Leslie Smith, professores da Faculdade Goldsmith, da Universidade de Londres, haviam desenvolvido poucos anos atrás. Depois de dez anos de pesquisas, Abercrombi percebeu que os alunos da Universidade de Londres obtinham um aprendizado melhor dos diagnósticos quando trabalhavam em grupos e não individualmente (BRUFFE, 1984).

No começo da década de 1970, alguns professores de universidades americanas perceberam a enorme dificuldade que os calouros possuíam para adaptar-se à nova realidade universitária. Sendo assim, muitos iniciaram pesquisas e desenvolveram trabalhos acerca do EC. Na mesma década ocorreu em Tel Aviv, Israel, a primeira conferência com o objetivo de discutir sobre o ensino cooperativo (JOHNSON; JOHNSON 1992, 1998, apud GILLIAM, 2002).

Chamaremos de EC qualquer prática que, através da formação de grupos, propicie a criação de um ambiente interacionista e se baseie na construção coletiva de conhecimento e na troca deste entre os indivíduos participantes do processo (MICHENER et al., 2005; ROBBINS, 2005, apud, TRACTENBERG, BARBASTEFANO, STRUCHINER, 2007).

\section{O EC NO BRASIL NOS DIAS DE HOJE}

No Brasil o EC ocorre pela difusão e implantação das Comunidades de Aprendizagem (CA) em algumas escolas públicas. Podemos entender a CA como 
uma atividade que é desenvolvida unindo todos os sujeitos da comunidade escolar aos princípios interacionistas e colaborativos do EC no processo de ensinoaprendizagem. A CA utiliza também o trabalho em grupo como um instrumento facilitador do aprendizado. No entanto, a participação da comunidade escolar é de fundamental importância, onde os grupos são coordenados por voluntários que têm como objetivo auxiliar o professor na condução da aula.

Uma das funções dos coordenadores é, por exemplo, indicar ao professor, quando necessário, problemas no desenvolvimento do conteúdo ou das atividades no grupo pelo qual ele está responsável, em relação ao planejamento da disciplina. Dessa forma, a CA experimenta uma incessante transformação, uma vez que a comunidade envolvida nesse processo de aprendizagem está imersa em um permanente ambiente de reflexão de seu próprio fazer (SCORTEGAGNA, OLIVEIRA, MOLLETA, 2007).

A concepção das CA surgiu na Espanha como uma tentativa de solucionar o fracasso escolar e melhorar a convivência nas escolas. Ela vem sendo desenvolvida pelo Centro Especial de Investigação em Teorias e Práticas Superadoras de Investigação e Ação Social e Educativa (CREA), da Universidade de Barcelona, desde a década de 1990 e pelo Núcleo de Investigação e Ação Social e Educativa (NIASE), da Universidade de São Carlos/Brasil, desde o início dos anos 2000 (GABASSA, MELLO, BRAGA, 2012).

Nos moldes da CA, o planejamento de uma aula está submetido à orientação direta do coordenador (tutor)-sob o acompanhamento do professor. 0 coordenador orienta os alunos, de um determinado grupo, que tenham concluído suas tarefas antes do prazo estabelecido, a ajudarem os demais componentes do grupo e, em um segundo momento, os demais grupos. Com isso, consegue-se uma aceleração do aprendizado do alunado de forma homogênea.

Tem-se observado uma crescente utilização das CAnas escolas públicas brasileiras, em particular, na cidade do Rio de Janeiro, onde através de uma parceria pública-privada ela tem sido introduzida em uma escola selecionada pela Secretaria Municipal de Educação (SME-RJ), sendo o treinamento dos profissionais da educação pública de responsabilidade da instituição privada.

\section{Principais ASPECTOS do EC}

Um ganho importante com a prática colaborativa é a criação de um ambiente propício para o que conhecemos como autonomia cognitiva, que se trata da capacidade que o alunopossui de reunir ferramentas para resolver um problema ou exercício, sem que haja dependência de informações externas. A prática colaborativa, mesmo focando na construção coletiva de um determinado conhecimento, permite ao aluno reunir e apresentar maneiras de posicionar-se diante das diversas opiniões dadas a um mesmo questionamento, além de levá-lo 
também a desenvolver formas de se colocar e, consequentemente, de ser ouvido dentro de seu grupo.

Vale destacar a necessidade de aplicar, em algum momento, avaliações e exercícios de forma individual para analisar se os alunos integrantes de cada grupo estão se apoiandonos mais bem preparados ou se está havendo uma troca constante e harmoniosa de informaçõesentre todos os componentes do grupo. A avaliação individual também serve para distinguir o aluno que somente copia a resposta daquele que absorve informações de terceiros e as incorpora como ferramentas.

O EC também tem a função de auxiliar os alunos a aperfeiçoar a comunicação entre eles, criando um ambiente socialmente interessante, de forma a proporcionar discussões em torno dos temas propostos pelo professor e que possibilitem a construção do conhecimento. Portanto, os alunos envolvidos nesse processo podem ter ganhos em termos de habilidades sociais que extrapolam a escola e os acompanharão por toda a vida.

No EC, o docente assume um papel diferente do que assumiria em uma aula tradicional, pois ele se afasta da característica principal do ensino tradicional de ser o único detentor do conhecimento e passa a ser o condutor de todo processo de construção do conhecimento. Com o desenrolar da aula, o mesmo deve fazer interferências constantes em cada grupo para estimular o debate e a convivência, ordenar e direcionar as ideias, analisar a maneira com que as interações estão acontecendo e verificar o andamento, de forma individual, do desenvolvimento de cada aluno perante o conteúdo trabalhado.

Cabe ao professor também, ao final da aula, retornar ao papel de protagonista para que tudo que tenha sido discutido ao longo da aula tenha uma conclusão que respeite o rigor matemático do assunto, fechando assim uma linha de raciocínio e caracterizando o EC como uma prática pedagógica e não como uma reunião desordenada de ideias.

Dessa forma, o professor no EC se torna reflexivo, analisador e pesquisador, pois ele deve buscar o aprimoramento de sua prática pedagógica (FINKEL, MONK, 1983, apud,BARBOSA, CONCORDIDO, 2009). O docente abandona a reprodução das práticas tradicionais e pragmáticas e aprimora seu trabalho em sala de aula. Sendo assim, o professor consegue contribuir na construção de um ambiente educacional democrático, onde todos os envolvidos na prática colaborativa terão a oportunidade de entender sobre o meio educacional no qual estão inseridos.

\section{A PRÁTICA COLABORATIVA}

A forma de organização e desenvolvimento de uma aula é fator fundamental para que a prática do ECvenha a lograr êxito.Destacamos a 
importância de que o professor deva ter um bom conhecimento sobre o perfil dos grupos de alunos com os quais pretende desenvolver a prática colaborativa. Alguns dados devem ser levantados como, por exemplo, desempenho em avaliações, frequências nas aulas, comportamento durante as atividades, grau de socialização, etc. Esse levantamento irá contribuir para a plena aplicação dessa metodologia e, consequentemente, a possibilidade de que esta venha a ter 0 sucesso desejado.

A fim de que tenhamos um controle adequado das atividades programadas, devemos dividir a turma em grupos de 3 a 5 alunos, buscando o maior grau de heterogeneidade possível. Isto significa mesclar alunos com características distintas no que diz respeito ao desempenho escolar e às suas vivências, possibilitando a construção de um ambiente mais rico em termos de trocas de experiências e de aprimoramento de seus conhecimentos.

A aula deve se iniciar com uma rápida exposição do assunto pelo professor, respeitando o planejamento já elaborado, em termos dos pré-requisitos e dos objetivos a serem alcançados e, em seguida, as atividades devem ser propostas aos grupos. Os grupos, por sua vez, devem realizá-las, de forma interativa, em que as dúvidas são sanadas pelos próprios colegas no grupo e, em caso de necessidade pelo professor. É possível também que, alcançado um determinado grau de maturidade, as discussões possam ser estendidas entre os grupos. Assim, as soluções dos exercícios propostos e das várias situações-problema colocadas surgem de forma coletiva.

No final da aula, o professor deve fazer o fechamento da atividade desenvolvida, podendo envolver a correção de exercícios pendentes, reforço de pontos ainda não suficientemente bem entendidos e observações complementares.

Cabe ressaltar que no EC, apesar de este ser uma prática pedagógica bem definida, o docente é livre para criar, adaptar e reorganizar seus métodos a fim de atendê-lo de acordo com sua sala de aula, sua estrutura escolar e sua realidade pedagógica. No entanto, o professor deve sempre focar qualquer nova ideia na construção coletiva do conhecimento.

Os objetivos do EC podem ser caracterizados por toda e qualquer transformação que o aluno obtenha e que beneficiará seu desenvolvimento como cidadão atuante na sociedade, ciente de seus atos e sua importância no mundo que vive em constante mudança, de forma que os ganhos alcançados em termos de socialização sejam tão relevantes quanto aqueles relacionados às habilidades intelectuais (GOODSELL et al, 1992, apud, BARBOSA, CONCORDIDO, 2009).

Considerando a grande dificuldade histórica dos alunos em aprender Matemática, por ser um ramo do conhecimento que envolve um pensamento abstrato, ou por defasagens que prejudicam a sequência do desenvolvimento do pensamento matemático, podemos levar em conta que qualquer evolução que o 
aluno obtenha no relacionamento com a Matemática será um êxito obtido pela prática colaborativa.

\section{A EDUCAÇÃo de JOVENS E ADULTOS}

A educação de jovens e adultos no Município do Rio de Janeiro foi implantada em 1984 em três escolas como um projeto alternativo para adolescentes das classes populares, entre 14 e 20 anos. Seu currículo era composto pelas disciplinas do núcleo comum adotado naquele período, além de aulas de técnicas comerciais, inglês, artes industriais, artes plásticas, educação para o lar e educação musical.

Também em 1985, o poder público constatando a existência de muitos jovens analfabetos, principalmente, nas camadas mais pobres, instituiu a Educação Infantil como parte do Programa Especial de Educação (PEE), sendo implantado em 20 CIEP's (Centro Integrado de Educação Pública) no horário noturno. O Programa de Educação de Jovens e Adultos (PEJA) foi criado como Programa de Educação Juvenil, pois era uma das metas do PEE. Em termos estruturais, o PEJA deveria funcionar com o máximo de 20 turmas por CIEP e com 15 alunos por turma. Possuía carga horária de quatro horas diárias: $18 \mathrm{~h}$ às $19 \mathrm{~h}$, jantar; 19 h às 21 h, aula; 21 h às 22 h, Educação Física ou Artes (FAVERO, BRENNER, 2006).

Como consequência da reivindicação dos alunos e dos profissionais que nele atuavam, o PEJA foi ampliado em 1987 para poder atender a todos que o procuravam com um nível de escolaridade mais avançado como também aqueles que foram alfabetizados pelo programa e desejavam seguir em seus estudos.

Em seu primeiro momento, o PEJA não emitia certificados (só foi autorizado a partir de 1999, pelo parecer 03/99 do Conselho Municipal de Educação), pois não era reconhecido pelos Conselhos de Educação, tanto o municipal como o estadual. A maneira encontrada de encaminhar os alunos para a $5^{a}$ série (atual $6^{\circ}$ ano) era transferir os alunos para o ensino supletivo, que existia conjuntamente com o PEJA e o ensino regular noturno, que foi instituído em 1988 e que visava atender aos jovens e trabalhadores de até 20 anos que desejavam continuar seus estudos e completar sua escolaridade básica(FAVERO, BRENNER, 2006).

Em 1998, a Secretaria Municipal de Educação apresentou ao Conselho Municipal de Educação uma proposta de implantação do $2^{\circ}$ segmento do Ensino Fundamental ao PEJA e a regulamentação do $1^{0}$ segmento. Nesse mesmo ano um convênio com o Fundo Nacional de Desenvolvimento da Educação (FNDE) permitiu uma formação para os professores que atuariam no programa.

A partir de 1998, depois do convênio com o FNDE, o PEJA começou a receber recursos e isso possibilitou a sua consolidação e crescimento para o atual panorama educacional em que se encontra (RIO DE JANEIRO, 2013). 
As principais características do PEJA são: (i) Ensino não seriado, acelerativo e progressivo, realizado de forma presencial, em horário noturno, distinto do ensino supletivo e do regular noturno. (ii) Cada turma deve ter no máximo 25 alunos e cada unidade escolar, um mínimo de 100 alunos. (iii) Organizado em dois segmentos: PEJA I, correspondendo ao $1^{0}$ segmento do Ensino Fundamental, e PEJA II, correspondendo ao $2^{\circ}$ segmento; cada segmento desdobrado em dois blocos, onde cada um deles perfaz, respectivamente, 400 horas/anuais (PEJA I) e 800 horas/anuais (PEJA II).

No PEJA I é iniciado o Bloco 1 , em que aluno vivencia o processo inicial de alfabetização, esta entendida como a aquisição da base alfabética da escrita e na capacidade de relacionar texto e contexto. No Bloco 2, o aluno amplia e aprofunda a relação texto e contexto, a partir de uma abordagem interdisciplinar que diferentes áreas do conhecimento teriam em comum.

No PEJA II são realizadas atividades presenciais (se possível em sala ambiente) que propiciem uma atmosfera adequada e motivadora para o aluno. Nesta etapa, as interações entre aluno e professor ocorrem de maneira direta.

As turmas do PEJA são formadas por alunos com idade igual ou superior a 17 anos e, excepcionalmente, de 15 e 16 anos se houver autorização da direção da escola ou da Coordenadoria Regional de Educação-CRE. Parte dos alunos se dirigem ao PEJA, no turno da noite, devido ao desempenho abaixo do exigido no ensino regular. Essa é uma situação também de interesse da escola, uma vez que diminui o índice de reprovação. Outra parte procura o PEJA para completar sua escolaridade, visando uma colocação melhor no mercado de trabalho. Uma parcela de alunos que merece destaque é aquela que está em uma faixa etária acima de 65 anos, buscando completar o Ensino Básico por uma questão de satisfação pessoal. Um fato que merece ser mencionado é que existe uma evasão grande dos alunos, pois, como as aulas se dão no período da noite, esses alunos, em geral, sentem-se extenuados após o dia de trabalho.

\section{Metodologia}

A experiência que será narrada a seguir foi realizada em uma Escola Municipal, de período integral, localizada no bairro do Andaraí, no município do Rio de Janeiro. Desde 2012 a escola lançou mão de grupos colaborativos para tentar recuperar os alunos que não foram aprovados e que continuavam a frequentar a escola. Após obter certo êxito nessa recuperação de alunos, em 2013, o corpo docente resolveu implantar práticas colaborativas na escola como um todo.

A estruturação dos grupos, também chamados de família, foi realizada pelaequipe de professores. Esses grupos eram compostos por alunos do mesmo ano, mas não necessariamente da mesma turma. Ao longo do ano, a formação 
dos grupos era reavaliada e alterada caso fosse necessário em função do rendimento.

Os alunos tinham suas aulas da forma tradicional noturno da manhã, onde os professores transmitiam os conteúdos. Noturno dos tarde eles se reuniam nas famílias para realizarem as atividades elaboradas pelos professores (geralmente exercícios), sob a supervisão de um professor da escola.

A partir de setembro de 2013, a escola passou a adotar a CA apenas nas turmas de 90 ano e somente no ensino de Matemática, como um projeto experimental. As práticas colaborativas eram utilizadas apenas em um tempo de aula, onde o professor preparava um conjunto de5 atividades para os grupos formados, nos quais os alunos tinham 10 minutos para resolvê-los. Dessa forma, ao longo de um tempo de 50 minutos, todos os grupos teriam resolvido todas as atividades propostas. Cabia ao professor também, em outro tempo de aula desse mesmo dia ou não, resolver e corrigir os exercícios.

\section{O Ensino Colaborativo no PEJA: ensinando o Conceito de função}

As atividades foram desenvolvidas em novembro e dezembro de 2013, perfazendo um total de 7 dias de aulas, com 4 horas aula em cada dia. As atividades envolveram duas turmas- A e B - de uma Escola Municipal do Rio de Janeiro, localizada no bairro de Copacabana. Essas turmas estavam na unidade do PEJA II,correspondente ao $9^{\circ}$ ano do Ensino Fundamental, com média de idade de 32 anos.Utilizou-se o ensino colaborativo na turma A e essa escolha deveu-se ao fatode ela possuir alunos com maior dificuldade do que aqueles da turma $B$.

A escolha de usar o EC no PEJA deve-se, principalmente, ao fato desse programa estimular o uso de novos métodos de ensino que sejam diferentes do modelo tradicional. Outro aspecto marcante das turmas do PEJA é a falta de motivação, pois, em geral, encontramos alunos cansados, como já apontamos e que ficaram muito tempo fora da escola.Um elemento também motivador para o uso da prática colaborativa foi a acentuada diversidade de conhecimentos, experiências e objetivos de vida trazida pelos alunos, além de diferentes ritmos de aprendizagem apresentados em sala de aula. Na prática colaborativa, o aluno mais rápido vai se tornando monitor do grupo, ou seja, ao terminar a atividade, ele se coloca a disposição do grupo para ajudar àqueles cujo processo de entendimento é mais lento.

O tópico a ser desenvolvido foi funções reais de uma variável real, que tinha como pré-requisitos para realização das atividades o conceito de plano cartesiano e valor numérico.

O conceito de função proporciona ao professor a possibilidade de elaborar uma grande quantidade de atividades, que invariavelmente envolve a 
compreensão de gráficos e tabelas, seguindo as orientações curriculares da SMERJ (Rio de Janeiro, 2013).

A definição de função que se encontra no caderno pedagógico da SME-RJ, diz que: "uma relação entre dois conjuntos $A$ e $B$ é uma função de $A$ em $B$, quando todos os elementos $x \in A$ têm seu correspondente $y \in B$ e cada $x \in A$ possui apenas um correspondente $y \in B^{\prime \prime}$.

O caderno pedagógico é um material confeccionado pela SME-RJ, que visa estruturar o desenvolvimento dos conteúdos ao longo dos bimestres em todas as escolas da rede municipal de ensino.

Todas as atividades desenvolvidas basearam-se na relação entre as diversas representações de função. Os alunos também foram conduzidos a perceber o papel desempenhado pelo conceito de função em outras disciplinas e como ela se mostra nas relações do cotidiano.

Vale salientar que cada atividade tentou propiciar aos alunos a possibilidade de se trabalhar em grupo e argumentar sobre suas dúvidas e/ou entendimentos acerca do assunto abordado, além de permitir constantes intervenções ao longo do processo de sua realização.

Como preparação para as atividades, o conceito de função foi apresentado em duas aulas. A dificuldade em resolver os exercícios foi um fato que fez com que todos começassem a olhar para o EC como um facilitador no entendimento das atividades, ou seja, cada exercício que um aluno não conseguia realizar ou interpretar ele buscava auxílio dentro de seu próprio grupo como forma de compreender e realizar a atividade proposta.

As atividades foram desenvolvidas em 3 dias, com 3 aulas de 60 minutos em cada dia, em um total de 9 horas aula de atividades. A turma A foi dividida em 4 grupos de 3 ou 4 alunos, dependendo da frequência diária.

A primeira atividade foi composta de três questões, que abordavam a condição para uma relação ser uma função, os conceitos de domínio, contradomínio e imagem de uma função e situações-problema para verificar se houve o correto entendimentos dos conceitos abordados.

A segunda atividade, a partir da definição de função, abordada na atividade anterior, envolveu a análise gráfica. A ideia foi levar o aluno a relacionar diferentes representações e associá-las ao mesmo conteúdo. As questões envolveram, além das definições dadas na atividade 1 , as relações entre os números do eixo $x$ e do eixo y através da representação de função e também perceber que a notação $f(x)=y$ significa que existe uma relação entre os números que representam $x$ e $y$.

A terceira atividade visou integrar três formas de apresentar uma função: sua forma gráfica, sua forma algébrica e na forma de diagrama. O uso da prática 
do EC foi novamente importante, pois a maior parte dos alunos possuía dificuldade em resolver a questão envolvendo a parte algébrica. Porém, o tempo foi otimizado com o auxílio de cada grupo, uma vez que cada um deles foi cuidadosamente formado de tal modo que cada grupo possuísse pelo menos um aluno que dominava esse conceito.

O objetivo da quarta atividade, colocada no Apêndice como exemplo das atividades desenvolvidas, foi mostrar para os alunos a importância da representação gráfica de função, utilizando material elaborado com questões extraídas de provas do Exame Nacional do Ensino Médio (ENEM).

\section{ANÁLISES DOS RESULTADOS OBTIDOS NAS AVALIAÇÕES}

Foram aplicadas duas avaliações na turma $A$, sendo a primeira em grupo e a outra individual. $O$ objetivo da avaliação em grupo, nesse tipo de abordagem, é caracterizar o andamento e a evolução dos grupos em relação ao conteúdo trabalhado. Já a avaliação tradicional, nesse contexto, deve ocorrer devido à necessidade de um instrumento de diagnóstico, que ofereça uma informação mais detalhada de cada aluno, no que concerne o desenvolvimento do processo de aprendizagem, bem como permita identificar aqueles alunos que apenas se apoiam no trabalho do grupo, ou ainda aqueles que, mesmo possuindo a intenção de aprender, não conseguem compreender o que está sendo pedido. Para uma análise mais eficaz do desempenho dos alunos, nesse processo avaliativo, as duas provas devem apresentar questões com o mesmo nível de dificuldade.

Na turma B, a avaliação feita em grupo na turma $A$ foi dada na forma de revisão para a prova, sem a atribuição de nota. $O$ desempenho da turma $A$ foi bem superior na avaliação em grupo, em que a média foi 8,0, enquanto que na avaliação individual a média foi 5,2 . Certamente, essa diferença se deve à divisão dos grupos, uma vez que eles foram formados de maneira que em cada um deles havia, pelo menos, um aluno que tinha se destacado previamente no sentido de apresentar um bom desempenho em outras avaliações.

Existem pelo menos duas explicações para essa discrepância entre as notas em uma mesma turma. A primeira é que parte dos alunos estava preocupada apenas com a aprovação e não aproveitou a dinâmica proporcionada pelo EC em termos de interação, o que leva à construção do conhecimento de forma coletiva. A outra explicação é que alguns alunos, mesmo participando das atividades de forma adequada, necessitavam ainda de um atendimento mais individualizado. Um ponto interessante que vale ser mencionado é a afirmação de todos os alunos, ao final de cada aula, que a maneira com que o conteúdo tinha sido trabalhado foi agradável, o que contrastou com a maioria que afirmava não gostar das aulas de Matemática antes do início das atividades. 
No que diz respeito à avaliação individual, quando comparamos as duas turmas, verificamos uma maior homogeneidade no desenvolvimento da aprendizagem na turma $A$ em relação à turma $B$, uma vez que apenas um aluno obteve nota acima da média, e dois alunos ficaram com notas bem abaixo. Esse não foi o quadro observado na turma $B$, onde houve uma maior distância entre 0 nível de conhecimento dos alunos, pois metade dos alunos conseguiu notas maiores que 8,0 e a outra metade ficou com notas abaixo de 6,0; a média foi 6,6.

Quando comparamos os resultados das duas turmas, observamos que apesar dos resultados serem próximos, o que foi alcançado pela turma A merece ser destacado, já que essa apresentou de forma clara um maior ganho em termos de socialização e uma melhor convivência com a Matemática.

\section{CONSIDERAÇões FinAIS}

Nesse trabalho apresentamos algumas sugestões acerca do emprego de práticas colaborativas, a partir de uma experiência realizada em uma escola pública do Município do Rio de Janeiro.

Apesar dos esquemas colaborativos serem bastante conhecidos em diversas partes do mundo, sua utilização no Brasil é bem recente, o que leva muitos educadores a acreditar que este é um método de difícil aplicação. De fato, a preparação do professor frente a esse novo desafio requer um grande estudo do tema e um profundo conhecimento da turma que, por sua vez, precisa também ser preparada para a utilização dessa metodologia.

Diversas dificuldades podem ocorrer na implantação de EC, já que a turma será dividida em pequenos grupos. Isso pode trazer problemas em relação à disciplina, levando a um ambiente de vozearia e dispersão. $O$ tempo disponível para aplicação pode ser outra fonte de dificuldade, pois muitos colégios possuem um número pequeno de aulas semanais de Matemática e, por vezes, essas aulas não se dão em sequência; uma aula de 50 minutos é muito pouco tempo para o pleno desenvolvimento do trabalho em um esquema colaborativo.

Outro problema que surge, invariavelmente, se deve ao fato de experiências como essa não fazerem parte de uma proposta pedagógica coletiva da escola. Dessa forma, como se trata da ação, em geral, de apenas um professor, não se cria o hábito de estar imerso em um EC e sempre muito tempo é perdido na preparação das atividades.

O desenvolvimento dessa experiência justifica-se na medida em que se procurou estruturar práticas colaborativas em sala de aula, aplicá-las e aperfeiçoálas no sentido de oferecer a possibilidade de um aprendizado diferenciado para os alunos, visando não só uma melhor performance deles nas avaliações em Matemática, mas também uma melhoria na formação global. 
Não existe uma receita infalível para que as aplicações do EC logrem êxito, cabendo, obviamente, ao professor tentar adaptar as práticas envolvidas no processo à turma e suas peculiaridades. Muitas vezes será necessário perder mais tempo na preparação dos alunos para as atividades, reorganizar os grupos e até mesmo readaptar as abordagens e as avaliações.

Apesar de haver uma certa tradição na aplicação de atividades em grupo no Brasil, a utilização do EC no auxílio do processo de ensino-aprendizagem ainda é um tema que demanda mais estudo e mais experiências, devido principalmente ao número reduzido de professores que se dispõe a usá-lo à enorme heterogeneidade encontrada nas redes escolares no Brasil em termos de preparação e desempenho. Mas, essa experiência, em especial, foi muito bem sucedida em um ponto fundamental na formação dos alunos envolvidos, ou seja, a formação da cidadania. Além de uma melhor aceitação da Matemática pelos alunos, houve uma maior socialização, isto é, uma melhora comportamental, em termos de saber compartilhar opiniões e respeitar as vivências e as experiências de seus colegas.

\section{REFERÊNCIAS}

BARBOSA, A. C. L. S. Abordagens educacionais baseadas em dinâmicas colaborativas online. 2008; 316 f. Tese (Doutorado em Educação) - Faculdade de Educação, Universidade de São Paulo, São Paulo, 2008. Disponível em: <http://www.teses.usp.br/teses/ disponiveis/48/48134/tde-12062008134225/publico/TeseAnaCristinaLimaBarbosa.pdf> Acesso em: 05 jan. 2014.

BARBOSA, A. C. de C.; CONCORDIDO C. F. R. Ensino colaborativo em ciências exatas. Revista Eletrônica do Mestrado Profissional em Ensino de Ciências da Saúde e do Ambiente. Rio de Janeiro. v. 2, n. 3, p. 60-86, dez. 2009.

BRASIL, PARÂMETROS CURRICULARES NACIONAIS (PCNs). Matemática. Ensino fundamental. Quarto ciclo. MEC/SEF, 1998.

BRUFFEE, K. A. Collaborative Learning and the "Conversation of Mankind".

College English, v. 46, n. 7, p. 635-652, nov. 1984.

FAVERO, O.; BRENNER, A. K. Programa de educação de jovens e adultos (peja). Programa de Pós-Graduação em Educação, Grupo de Trabalho, n. 18, UFF, Rio de Janeiro, 2005. 
GABASSA, V.; MELLO, R. R.; BRAGA, F. M. Comunidades de aprendizagem: uma possibilidade para a escola contemporânea. In: ENCONTRO NACIONAL DE DIDÁDITA E PRÁTICAS DE ENSINO, 16., 2012, Campinas, Anais...Campinas: Junqueira \& Marin Editores, 2012, 12 p.

GAILLET, L. L. A historical perspective on collaborative learning. Journal of Advanced Composition, v. 14, n. 1, p. 93-110, 1994. Disponível em: <http://jaconlinejournal.com/archives/vol14.1/gaillet-historical.pdf >.Acesso em: 06 mar. 2014.

GALVÃO, E. C. B. Aprendizagem cooperativa e comunidade de práticas: possibilidades para a educação sociocomunitária. 2012. 213 f. Dissertação ( Mestrado em Educação) - Centro Univesitário Salesiando - UNISAL, São Paulo, 2012. Disponível em: <http://unisal.br/wpcontent/uploads/2013/04/DISSERTA\%C3\%87\%C3\%830 erica cristiane belon $\mathrm{g}$ alv\%C3\%A3o 2012.pdf>. Acesso em: 06 mar. 2014.

GILLIAM, J. $\mathrm{H}$. The impact of cooperative learning and course learning envionment factors on learning outcomes and overallexcellence in the community college classroom. 1840.16/3736/1/etd.pdf>. Acesso em: 06 mar, 2014.2002. 234 f. Tese (Doutorado em Eduacação) -Faculdade de Pós-Graduação, Universidade Estadual da Carolina do Norte, E.U.A., 2002. Disponível em: < http://repository.lib.ncsu.edu/ir/bitstream/.

RIO DE JANEIRO. Caderno Pedagógico, 90 ano (30 bimestre). Rio de Janeiro: Ediouro Gráfica e Editora LTDA, 2013.

. ORIENTAÇÕES CURRICULARES: $1^{\circ}$ AO 90 ANO. Matemática. SME-RJ, 2013.

- Secretaria Municipal de Educação. Gerência de Educação de Jovens e Adultos. Documentos Norteadores do PEJA. Rio de Janeiro, 2013.

- Secretaria Municipal de Educação.Conselho Municipal de Educação.Anexo do Parecer CME nº 2, de 29 de janeiro de 2013. Rio de Janeiro, 2013. 
SANTOS, I. S. F.; PRESTES, R. I.; VALE, A. M. Brasil, 1930 - 1961: Escola Nova, LDB e disputa entre escola pública e escola privada. Revista HISTEDBR On-line. Campinas, n.22, p.131 -149, 2006.

SCORTEGAGNA, P. A.; OliveIRA, R. C. S.; MOLETTA, A. K. In: EDUCERE, 7., 2007, Curitiba, Anais... Curitiba: 2007.

TEIXEIRA, Anísio S. A Pedagogia de Dewey. In: DEWEY, John. Vida e educação. Tradução e estudo preliminar por Anísio S. Teixeira. São Paulo: Melhoramentos; Rio de Janeiro: Fundação Nacional de Material Escolar, 1978.

TORRES, P. L.; ALCANTARA, P. R.; IRALA, E. A. F. Grupos de consenso: uma proposta de aprendizagem colaborativa para o processo de ensino-aprendizagem. Revista Diálogo Educacional, Curitiba, v. 4, n.13, p.129-145, set./dez. 2004.

TRACTENBERG, L.; BARBASTEFANO, R.; STRUCHINER, M. As vantagens do ensino colaborativo online: uma experiência aplicada ao ensino da matemática. In: ENCONTRO NACIONAL DE PESQUSA EM EDUCAÇÃO EM CIÊNCIAS, 6., 2007, Santa Catarina. Anais... Santa Catarina: 2007, 12 p. 
DOI: $10.12957 /$ e-mosaicos.2018.32359

APÊNDICE - Atividade 4

Questão 1(UNICAMP 2013): A figura abaixo mostra a precipitação pluviométrica em milímetros por dia ( $\mathrm{mm} / \mathrm{dia})$ durante o último verão em Campinas. Se a precipitação ultrapassar $30 \mathrm{~mm} / \mathrm{dia}$, há um determinado risco de alagamentos na região. De acordo com o gráfico, quantos dias Campinas teve este risco de alagamento?

Gráfico 1 - Gráfico da questão 1, atividade 4.

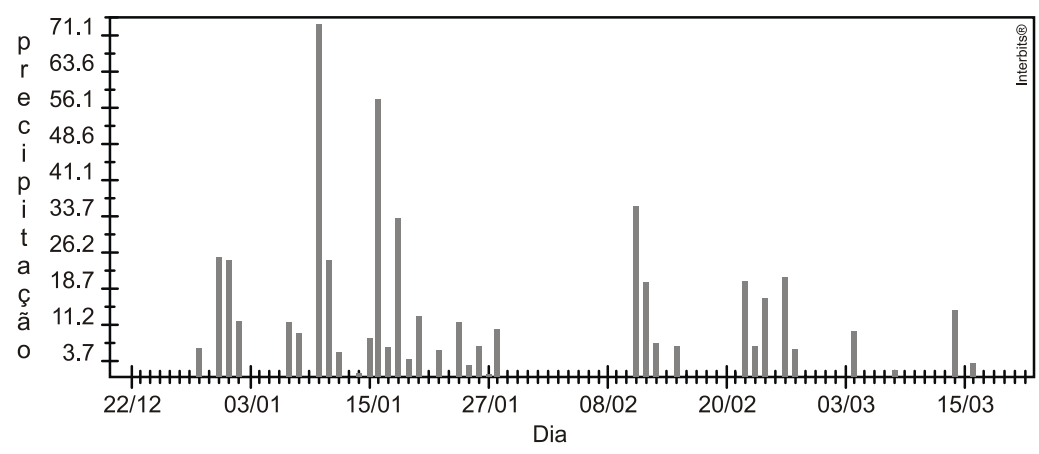

Fonte: Prova UNICAMP, 2013.

a) 2 dias. b) 4 dias. c) 6 dias. d) 10 dias.

Questão 2(ENEM 2012): O gráfico fornece os valores das ações da empresa XPN, no período das 10 às 17 horas, num dia em que elas oscilaram acentuadamente em curtos intervalos de tempo.

Gráfico 2 - Gráfico da questão 2, atividade 4.

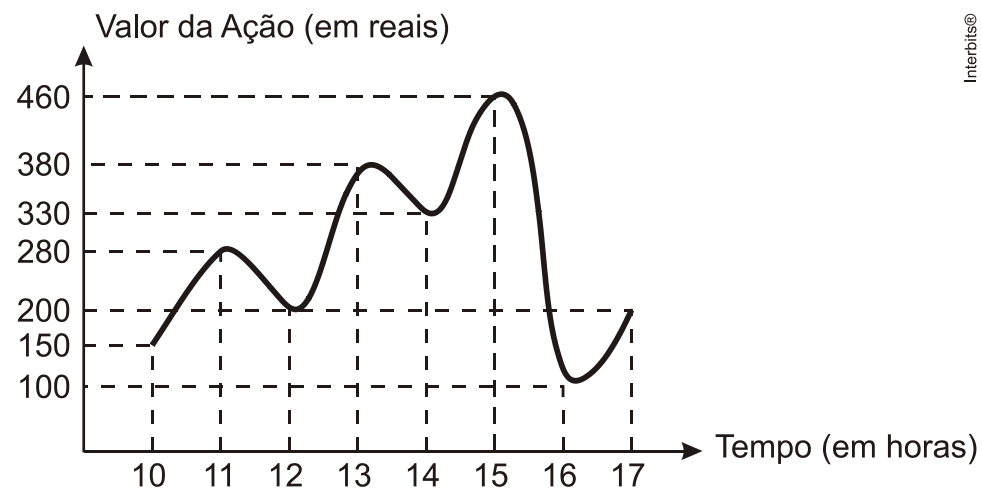

Fonte: ENEM, 2012. 
DOI: $10.12957 /$ e-mosaicos.2018.32359

Neste dia, cinco investidores compraram e venderam o mesmo volume de ações, porém em horários diferentes, de acordo com a seguinte tabela.

Tabela 1 - Tabela da questão 2 , atividade 4.

\begin{tabular}{|c|c|c|}
\hline Investidor & Hora da Compra & Hora da Venda \\
\hline 1 & $10: 00$ & $15: 00$ \\
\hline 2 & $10: 00$ & $17: 00$ \\
\hline 3 & $13: 00$ & $15: 00$ \\
\hline 4 & $15: 00$ & $16: 00$ \\
\hline 5 & $16: 00$ & $17: 00$ \\
\hline
\end{tabular}

Fonte: ENEM, 2012. negócio?

Com relação ao capital adquirido na compra e venda das ações, qual investidor fez o melhor
a) 1
b) 2
c) 3
d) 4
e) 5

Questão 3(ENEM CANCELADO 2009): Muitas vezes o objetivo de um remédio é aumentar a quantidade de uma ou mais substâncias já existentes no corpo do indivíduo para melhorar as defesas do organismo.Depois de alcançar o objetivo, essa quantidade deve voltar ao normal.Se uma determinada pessoa ingere um medicamento para aumentar a concentração da substância $A$ em seu organismo, a quantidade dessa substância no organismo da pessoa, em relação ao tempo, pode ser melhor representada pelo gráfico

a)

Gráfico 3 - Gráfico da questão 3, atividade 4.

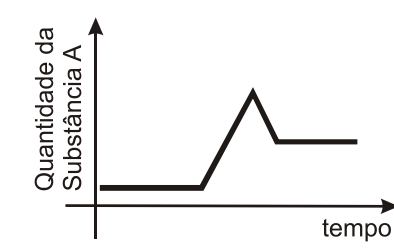

b)

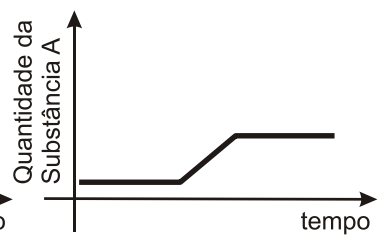

d)

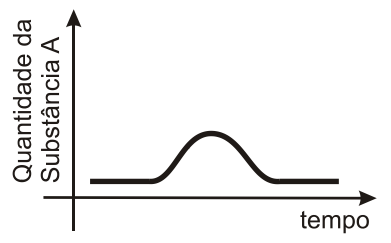

e) c)

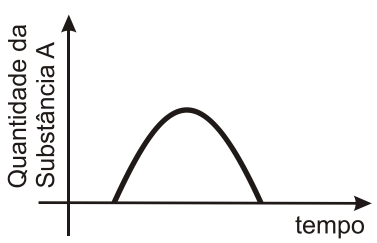

Fonte: ENEM cancelado, 2009.

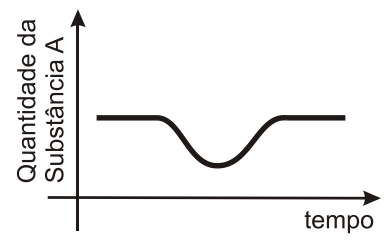


Questão 4(ENEM 2003): Após a ingestão de bebidas alcoólicas, o metabolismo do álcool e sua presença no sangue dependem de fatores como peso corporal, condições e tempo após a ingestão.O gráfico mostra a variação da concentração de álcool no sangue de indivíduos de mesmo peso que beberam três latas de cerveja cada um, em diferentes condições: em jejum e após o jantar.Tendo em vista que a concentração máxima de álcool no sangue permitida pela legislação brasileira para motoristas é $0,6 \mathrm{~g} / \mathrm{L}$, o indivíduo que bebeu após o jantar e o que bebeu em jejum só poderão dirigir após, aproximadamente,

Gráfico 4 - Gráfico da questão 4, atividade 4.

g/L Ingestão de álcool

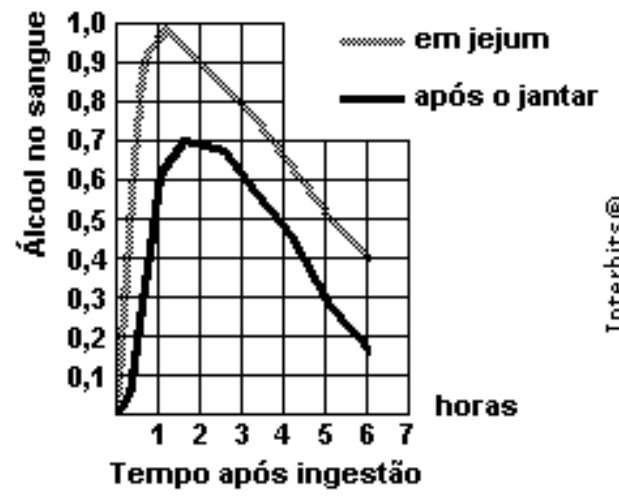

(Revista Pesquisa FAPESP ${ }^{\circ}$ 57. setembro 2000)

Fonte: ENEM, 2013.

a) uma hora e uma hora e meia, respectivamente.

b) três horas e meia hora, respectivamente.

c) três horas e quatro horas e meia, respectivamente.

d) seis horas e três horas, respectivamente.

e) seis horas, igualmente.

Questão 5(ENEM 2008): No gráfico a seguir, estão especificados a produção brasileira de café, em toneladas; a área plantada, em hectares (ha); e o rendimento médio do plantio, em kg/ha, no período de 2001 a 2008.

Gráfico 5 - Gráfico da questão 5, atividade 4. 
e-Mosaicos - Revista Multidisciplinar de Ensino, Pesquisa, Extensão e Cultura do Instituto de Aplicação Fernando Rodrigues da Silveira (CAp-UERJ) V. 7 - N. 16 - DEZEMBRO 2018 - ISSN: 2316-9303

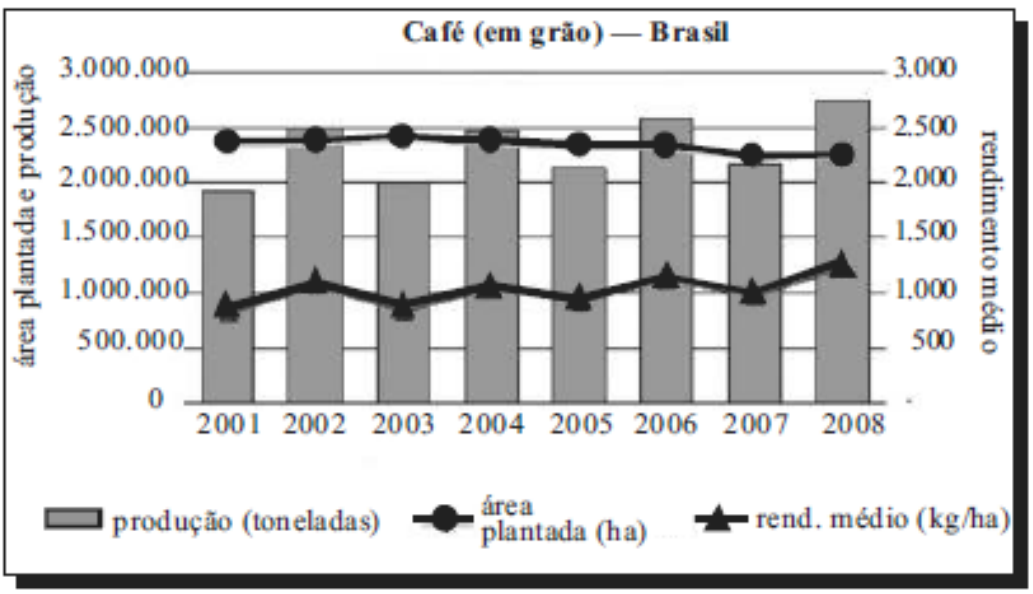

Fonte: ENEM, 2008.

A análise dos dados mostrados no gráfico revela que:

a) A produção em 2003 foi superior a 2.100 .000 toneladas de grãos.

b) A produção brasileira foi crescente ao longo de todo o período observado.

c) A área plantada decresceu a cada ano no período de 2001 a 2008.

d) Os aumentos na produção correspondem a aumentos no rendimento médio do plantio.

e) A área plantada em 2007 foi maior que a de 2001.

Recebido em 22 de janeiro de 2018

Aceito em 02 de maio de 2018 